\title{
Concept learning in mentally retarded Ss using three types of verbal labels
}

\author{
WYATT E. STEPHENS and MARILYN KOMECHAK, Texas \\ Christian University, Ft. Worth, Texas 76102
}

Three groups of mentally retarded Ss learned a concept using verbal labels from different linguistic form classes. The group using verb labels required more trials to criterion than the noun-label or adjective-label groups. These findings were similar to those reported previously for three groups of normal children equal in mental age to the present Ss. Questions were raised concerning the relationship between learning and transfer in normal and mentally retarded Ss on tasks requiring different form-class labels.

Numerous studies have demonstrated that verbal labels facilitate concept learning and transfer. This principle appears to hold both for children with normal intellect and those who are mentally deficient. The findings of Rasmussen \& Archer (1961), Cantor \& Hottel (1957), Smith \& Means (1961), and Smith, Means, \& Fishkin (1968) indicate that in Ss of normal and subnormal mental ability, pretraining in cue naming, when relevant to the subsequent task, enhances performance on concept learning problems of various types. Verbalization during concept learning tasks is another procedure which enhances various facets of concept learning and transfer, as demonstrated by the investigations of Gagne (1962), Barnett, Ellis, \& Pryor (1959), Kurtz \& Hovland (1953), Carey \& Goss (1957), Kendler \& Kendler (1961), and others.

One line of questioning which may be of considerable significance has received little investigation. Virtually all studies of the labeling process have employed labels of the noun form-class. Even studies using nonsense labels have presented them in syntactic patterns which indicate that they are serving a nominal function. Moreover, those studies employing labels which are not of the noun form-class have not reported the relative effects, if any, which labels of different linguistic form classes may have upon performance levels in concept learning.

Normative data describing early language development clearly demonstrate that labels from the noun form-class predominate in early childhood, but become increasingly less frequent with age, with a corresponding increase in verbs and adjectives in the spontaneous verbalization of children (McCarthy, 1930). Consequently, the appearance of form-class categories must be viewed as a developmental process with a relatively predictable sequence. Furthermore, it may be inferred that predominance of a given form-class in spontaneous verbal behavior indicates a focusing of the developing child upon the classes of objects, events, and experiences expressed in the linguistic form class which is predominant in his spontaneous verbal repertory. Thus the earliest stage of verbal behavior, the naming of environmental objects parallels the psycholinguistic development of the noun form-class, while the subsequent increase in frequency of verbs parallels a focus on environmental activity and object function.

Some writers (for example, Carroll, 1964) have claimed that the relationship between linguistic behavior and patterns of thinking is isomorphic, and that verbal behavior reflects the cognitive structure which characterizes the individual. Assessment of this hypothesis depends upon systematic manipulation of linguistic variables in an effort to reveal differential patterns of verbal behavior which may be related to different chronological ages and levels of ability.
An earlier study of average -seven- and eight-year-old children found that while verbal labels have a general facilitating effect upon concept learning, labels from different linguistic form-classes produce differential learning rates for identical stimulus items (Stephens, 1968). The purpose of the present study was to replicate the previous one, but with mentally retarded Ss in order to determine whether for this sample the use of noun labels, verb labels, and adjective labels produce different levels of performance on a concept learning task.

\section{METHOD}

The Ss were 30 mentally retarded children enrolled in public school classes for the educable mentally retarded. The mean IQ score was 60.13 with a standard deviation of 5.7. Mean chronological age was 152.33 months with a standard deviation of 25.44 months. The mean mental age was 85.35 months with a standard deviation of 35.9 months. Equal numbers of boys and girls were randomly assigned to three experimental groups. These were the noun-label group (NL), the verb-label group (VL), and the adjective-label group (AL).

The test procedure was identical to that reported earlier (Stephens, 1968). Briefly, each $S$ was presented with a series of geometric figures exhibiting seven variations constructed by systematically eliminating different portions of a $13 / 4$-in. square. The examiner's instruction to the three groups were identical except for minimal differences required to convey the form class membership of the label to be used. The NL group was instructed to find each figure which was an ORK, the VL group to find the figures which were ORKING, and the AL Ss to locate the figures which were ORKY.

In the leaming task each $S$ was presented the seven variations of the square figure in a series of seven blocks of seven trials, with each block including the seven possible variations of the basic figure in a randomized order. The $\mathrm{S}$ was required to learn that the figure with one side open was the appropriate response, regardless of the spatial orientation of the figure. Knowledge of results was provided after each trial, and the procedure continued until the $S$ completed one block of seven trials without error.

\section{RESULTS AND DISCUSSION}

Paired comparisons of groups revealed that the VL group required significantly more trials to a criterion of seven consecutive correct responses than the NL group $(t=2.79$, $p<.05)$. The AL group's performance was intermediate between the NL and VL groups, and did not differ significantly from either of them. All except one of the Ss attained criterion by the end of the fourth block of trials; this $S$ required five blocks.

The findings for these mentally retarded Ss were quite similar to earlier findings on identical tasks reported for three groups of children with average mental ability to whom the present Ss were matched in measured mental age (Stephens, 1968). Both the normal and the mentally retarded samples required more trials to learn the concept labeled with a verb, while the groups using noun labels and adjective labels learned somewhat more rapidly. Thus, the combined findings of the two studies suggest that varying the form-class label to be attached to similar geometric figures in a concept learning task produces differential learning rates. Furthermore, the findings indicate that concept learning under these circumstances is more closely related to mental age (as measured by standardized tests of intelligence) than to chronological age. 


\section{REFERENCES}

BARNETT, C. D., ELLIS, I. R., \& PRYOR. M. W. Stimulus pretraining and the delayed reaction in defectives. American Journal of Mental Deficiency, 1959, 64, 104-111.

CANTOR, G. N., \& HOTTEL, J. V. Psychomotor learning in defectives, as a function of verbal pretraining. Psychological Record, 1957, 7, 79-85.

CAREY, J. E., \& GOSS, A. E. The role of mediating verbal responses in the conceptual sorting behavior of children. Journal of Genetic Psychology, 1957, 90, 69-74.

CARROLL, J. B. Language and thought. Englewood Cliffs, N. J.: Prentice-Hall, 1964.

GAGNE, R. M., \& SMITH, E. C. A study of the effects of verbalization on problem solving. Journal of Experimental Psychology, 1962, 63, 12-18.

KENDLER, H. H., \& KENDLER, T. S. Effects of verbalization on reversal shifts in children. Science, 1961, 134, 1619-1620.

KURTZ, K. W., \& HOVLAND, C. I. The effect of verbalization during observation of stimulus objects upon accuracy of recognition and recall. Journal of Experimental Psychology, 1953, 45, 157-164.

McCARTHY, D. A. Language development of the pre-school child Minneapolis, Minn.: University of Minnesota Press, 1930.

RASMUSSEN, E. A., \& ARCHER, E. J. Concept identification as a function of language pretraining and task complexity. Journal of Experimental Psychology, 1961, 61, 437-441.

SMITH, M. P., \& MEANS, J. R. Effects of type of stimulus pretraining on discrimination learning in the mentally retarded. American Journa of Mental Deficiency, 1961, 66, 259-265

SMITH, M. P., MEANS, J. R., \& FISHKIN, S. Effects of naming upon learning and transfer of learning in the mentally retarded. American Journal of Mental Deficiency, 1968, 72, 637-647.

STEPHENS, W. E. Category usage of normal and subnormal children on three types of categories. American Journal of Mental Deficiency. 1966, 71, 266-273.

STEPHENS, W. E. Concept learning with three types of verbal labels. Psychonomic Science, 1968, 10, 225-226. 